de l'Institut Pasteur, 1897). L'auteur étudie spécialement la fonction des levures de la bière sur le lait et il arrive aux résultats suivants. Les analyses sont faites quatorze mois après l'ensemencement:

\begin{tabular}{|c|c|c|c|c|c|c|c|}
\hline & Controle & $\begin{array}{l}\text { Sacchar- } \\
\text { romyces } \\
\text { Frohberg }\end{array}$ & $\begin{array}{l}\text { Sacchar- } \\
\text { romyces } \\
\text { Meurant }\end{array}$ & $\begin{array}{l}\text { Sacchar- } \\
\text { romyces } \\
\text { Copeuhague }\end{array}$ & $\begin{array}{l}\text { Sacchar- } \\
\text { romyces } \\
\text { Bruxelles }\end{array}$ & $\begin{array}{l}\text { Sacchar- } \\
\text { romyces } \\
\text { Loweibran }\end{array}$ & $\begin{array}{l}\text { Sacchar- } \\
\text { romyces } \\
\text { Neukirchen }\end{array}$ \\
\hline $\begin{array}{l}\text { emps de la liquéfac- } \\
\text { tion de la gélatine } \\
\text { en mois........ }\end{array}$ & n & 然 & 2 & - & 3,5 & (5) & 6 \\
\hline Lactose en gr. par litre & 50,2 & 47,2 & 48,1 & 49,1 & 49,2 & 49,5 & 49,3 \\
\hline \multicolumn{8}{|l|}{ Caséine en solution par } \\
\hline litre. . . . . . , & 5,2 & 16,2 & 15,8 & 11,9 & 11,5 & 8,8 & 8,2 \\
\hline Caséine en suspension & 29,4 & 14,8 & 12,6 & 16,9 & 19,1 & 20,4 & 22,4 \\
\hline Caséine total par litre & 34,6 & 31,0 & 28,4 & 28,8 & 30,6 & 29,2 & 30,6 \\
\hline Ammoniaque par litre & 0,076 & 0,248 & 0,52 & 0,464 & 0,293 & 0,388 & 0,297 \\
\hline $\begin{array}{l}\text { Résidu minéral en solu- } \\
\text { tion. }\end{array}$ & 5,2 & 4.1 & 4.2 & 4.6 & 4.3 & 4.8 & 4.9 \\
\hline Résidu en suspension & 2,3 & 3,3 & 3,4 & 3,1 & 3,2 & 2,4 & 2,6 \\
\hline
\end{tabular}

Comme nous le voyons par ce tableau, l'énergie de la décomposition de nos torulas est beaucoup plus grande que celle des levures mentionnées. Plus tard, BeiJerinck (Central. f. Balteriolog., II, t. III. 1897), GREeT, BAHN et Wirl ont étudié la question de la protéolyse chez les levures, sans venir à des résultats définitifs. Généralement, on estime que l'enzyme est une trypsine, mais on doit remarquer que chez les levures cette enzyme n'est pas sûrement identique à une trypsine ordinaire, parce qu'elle agit dans un milieu strictement acide, tandis que la trypsine agit, comme nous le savons, seulement dans un milieu alcalin.

Notre torula appartient au groupe des torulacées que représentent les espèces comme : Torula Duclaux, Torula lactis Adametz, Torula Kephyr, Torula Tyrocola Beijerinck, Torula Kayser, Torula Mazé et Lactomyces inflans caseigrana Bochicchio. Elle ressemble surtout à $\bar{a}$ levure de Bochicchio et se distingue de celle-ci seulement parce qu'elle liquéfie la gélatine et qu'elle produit de l'acide, ce que ne fait pas le lactomyces nommé. A ce point de vue, elle représente alors pour ainsi dire une espèce nouvelle.

(A suivre.)

\title{
PRODUGTION D'UNE ODEUR ET D'UNE SAVEUR \\ DE " CARAMEL" DANS LES PRODUITS LAITIERS PAR LE STREPTOCOCCUS LACTIS (LISTER)
}

par Wilfrid SADLER B.S.A., M. Sc.,

Professeur de Laiterie à l'Université de la Colombıe Britannique, à Vancouver (Canada).

La présence, dans les produits laitiers, de l'odeur et de la saveur de " caramel " a été observée de temps en temps. Il est mêmè pro- 
bable que cette présence a été, et est, plus fréquente qu'une revue de la littérature scientifique à ce sujet pourrait le faire supposer, en raison de la variété des termes employés pour. décrire à la fois l'odeur et la saveur.

Dans une "note sur un organisme produisant un goût de lait brûlé ” [1] (1911), j'ai décrit un échantillon de lait reçu pour examen comme suit :

"Le lait était acide, et avait un arôme ressemblant à celui du caramel; tandis que la saveur était semblable à celle d'un lait qui aurait été cuit ou brûlé; en outre, la saveur était nettement amère, le lait étant ainsi tout à fait impropre à la consommation, tout au moins au point de vue de la dégustation \%.

Je trouvai que l'organisme en cause était une variété de Bacterium lactis acidi de LeICHManN, variété typique à tous égards, sauf qu'en. outre elle produisait l'arôme et la saveur distinets ci-dessus définis. Du beurre fait avec de la crème ensemencée avec cet organisme avait l'arôme et la saveur caractéristiques. En employant du lait ensemencé pour la fabrication de fromage, celui-ei avait les défauts ei-dessus signalés.

Duchadx [2] parle d'un goût de "brûlé " quelquefois observé dans des études sur l'amertume dans le lait. WEIGMaNN [3] (1911) observe que certaines espèces de Streptococcus lacticus donnent un goût de malt. En faisant du beurre expérimental avec de la crème infectée par les organismes donnant ce goût de malt, on obtient un produit ayant une saveur de brûlé ou de rôti. Leitch [4] (1918) a trouvé deux organismes du type Streptococcus lacticus donnant une saveur de brûlé au caillé pendant la fabrication du fromage, et au beurre fait de crème mûrie avec leur aide ; la saveur de brûlé était à la fois appréciable à l'odorat et à la dégustation. Dans une étude sur la flore bactérienne du beurre, commencée en 1919, SADLER et Vollum [5] obtinrent de beurre, fabriqué dans une laiterie spéciale, trois espèces qui produisirent l'odeur caractéristique de caramel dans le lait. Ces espèces étaient d'un type semblable au Streptococcus lactis à beaucoup d'égards; mais elles liquéfiaient la gélatine. KAYSER [6] (1921), en discutant du lait amer, se réfère à mon travail de 1911 : "SADLER nous a fait connaître des bactéries lactiques donnant le gaût amer au lait et au beurre ". Orla JENSEN [7] (1921), en indiquant que C.O. JENSEN isola des bactéries lactiques qui donnaient un goût de brûlé ou malté à la crème et au beurre, observe que le goût défini est souvent produit par des variétés de Streptococcus lactis. Dans une étude plus détaillée sur l'odeur de brûlé ou de caramel dans les produits laitiers, HAMMER et CoRDES [8] notent que la saveur de brâlé suggère à certains le caramel, à d'autres le lait condensé, et le malt à d'autres. MaC Donnell (1899), cité par les précédents [8] donna le nom de Bacterium lactis acidi maltigenum à une espèce pro- 
duisant de l'acide lactique, parce qu'elle produisait dans le lait une odeur et une saveur rappelant le malt. HAMMER et CorDES [8] clarifient la terminologie employée dans la description de cette maladie en supprimant l'emploi du mot "brûlé » et en adoptant, entièrement, comme dénomination de la saveur, le terme "caramel " précédemment employé par moi pour définir l'arôme caractéristique. Ils trouvèrent que cette saveur était commune dans la crème acide livrée aux beurreries de l'état d'Towa, et isolèrent des espèces de Streptococcus lactis de crème et de beurre ayant la saveur du caramel, d'un échantillon d'excrément de vache, et d'eau d'un bac de réfrigération d'une ferme d'Iowa. Ils montrèrent que les bactéries isolées étaient de la même espèce, produisaient l'odeur et la saveur caractéristiques dans du beurre expérimental fait avec de la crème infectée, et classifièrent expérimentalement l'organisme en question sous le nom de Streptococcus lacticus var. maltigenus.

\section{OBJet de LA PRÉSEnte Étude}

Il y a un peu plus d'un an, 15.000 livres de beurre fabriqué dans une laiterie de la Colombie Britannique furent trouvés invendables en raison d'une saveur spéciale désagréable. Un ancien étudiant (1), qui avait beaucoup d'expérience, fut envoyé à la laiterie. Aprés avcir effectué une visite détaillée de la laiterie, il rapporta les échantillons indiqués ei-dessous. A ce moment, la crème n'était pas pasteurisée dans cette laiterie.

Echantillons reçus au laboratoire :

a) Crème de chacun des 12 fournisseurs ; b) eau employée à la laiterie ; c) 6 livres de beurre qui avaient été en magasin, et qui avaient une saveur indésirable; d) 6 livres de beurre fabriqué pendant le séjour de Townsend, avec la meilleure qualité de crème classée; e) 6 livres de beurre fabriqué pendant le même séjour avec de la crème de seconde qualité.

N. B. - Townsend indique que $90 \%$ de la crème classée audessous de la "spéciale " l'était ainsi en raison d'une saveur amère.

Le beurre marqué $(e)$ avait une odeur et une saveur de caramel quand il fut déballé à l'arrivée au laboratoire; l'échantillon (d) n'avait pas les mêmes défauts à ce moment, mais une odeur et une saveur de caramel furent observées plus tard : l'arôme et le goût du beurre emmagasiné (échantillon $c$ ) étaient masqués par l'âge et la détérioration géné-

(1) Mr. C. T. Townsend, qui obtint plus tard la bourse W. C. Macdonaid, fut l'étudiant choisi pour cette visite. Il elassa les erèmes d'après leur origine à l'arrivée à la laiterie, fit lee essais chirniques nécessaires, fit aussi, avec le Directeur, divers barattages, rapporta de nemhreux échantillons et s'aequitta, en résumé, très bien de sa mission. Je suis trés oblig'́ à M. Towasend. 


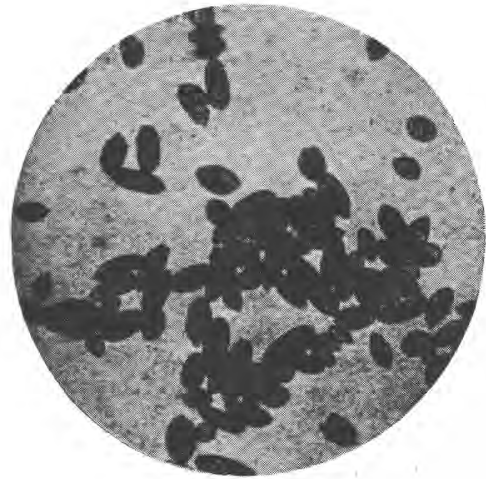

FIG. I

Spores de Cladosporium herbarium

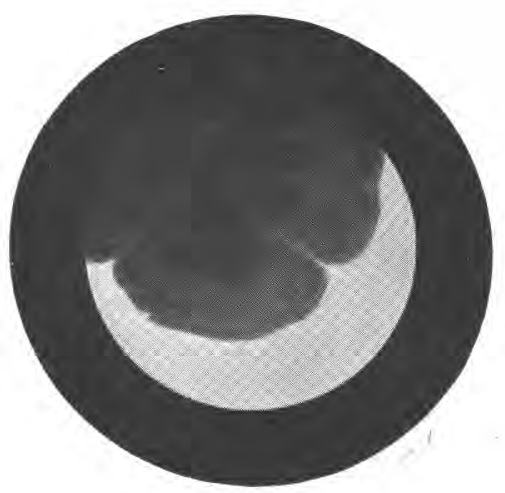

FIG. 3

[Colonies de Torula 39 sur gélatine

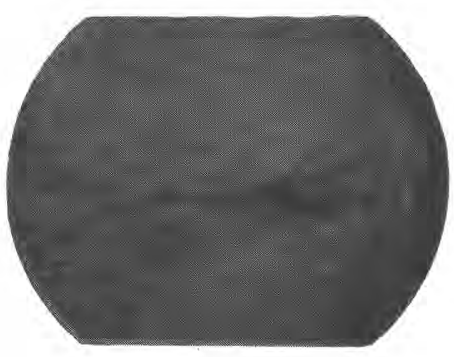

FIG. 2

Croissance des conidies du Cladosporium herbarium en chambre humide

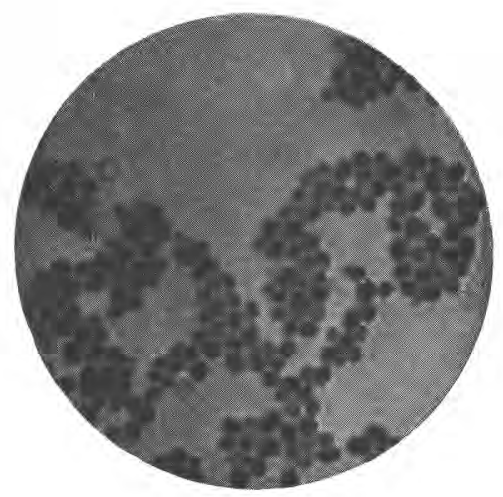

FIG. 4

Torula 39

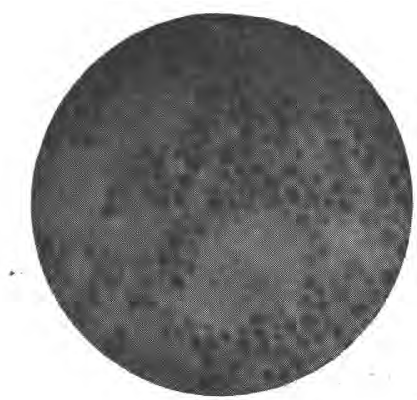

Fig. 5

Torula 40 


\section{MÉMOIRE SADLER}

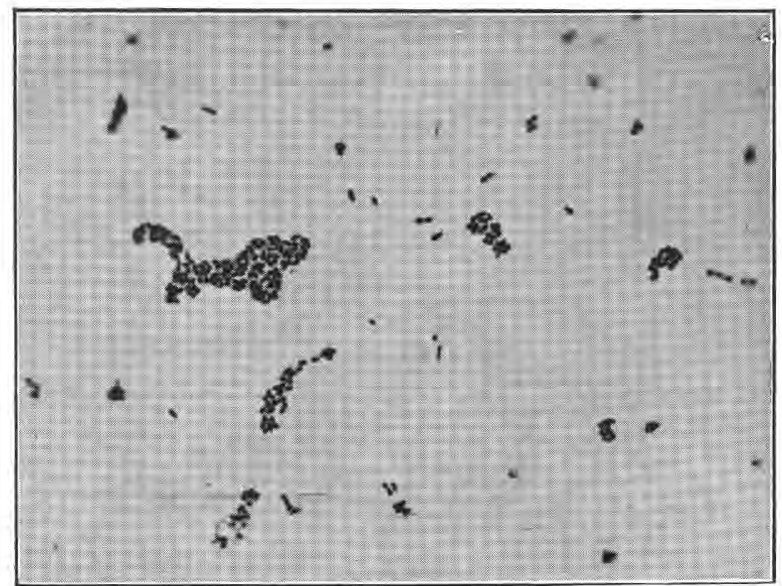

FIC. $1(1)$

Culture SA 30 sur sérum de lait-gélose, 27 heures à $21^{\circ} \mathrm{C}$. ;

Grossissement : 900 fois

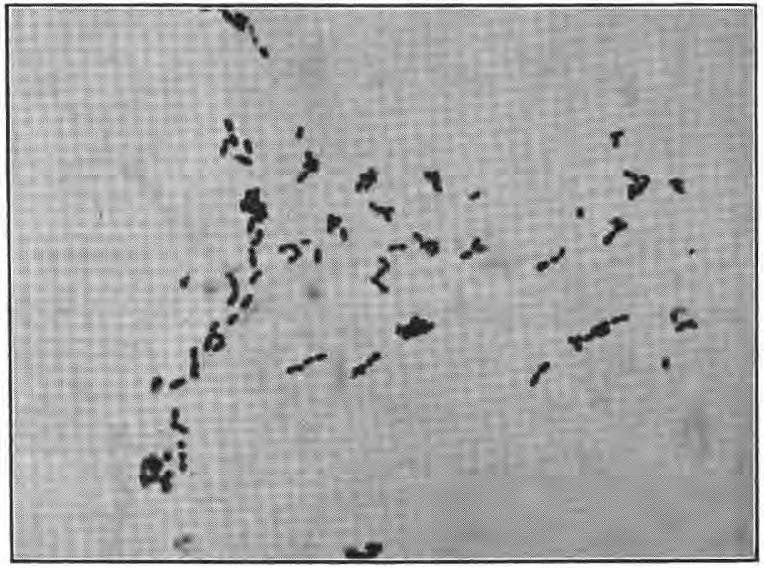

FIG. 2

Culture SA 30. Bouillon glucosé, 22 heures à $30^{\circ}$ C. ;

Grossissement : 900 fois

(1) Pour les photo-micrographies, on a utilisé l'oculaire compensateur de Zeiss.

Pour la fig. 1, le microscope de Zeiss : objectif achromatique à immersion dans l'huile $n^{\circ} 90(1.23)$; pour les fig. 3,4 et 5 , l'objectif aprochromatique à immersion dans l'huile $\mathrm{n}^{7} 90$ (1.3); pour la fig. 2, l'appareil de Leitz avec les mênıes objectifs que pour 3,4 .

Les 5 coupes ont été colorées au Gram. Pour la coupe 3, l'éosine a été employée comme contre-colorant. 


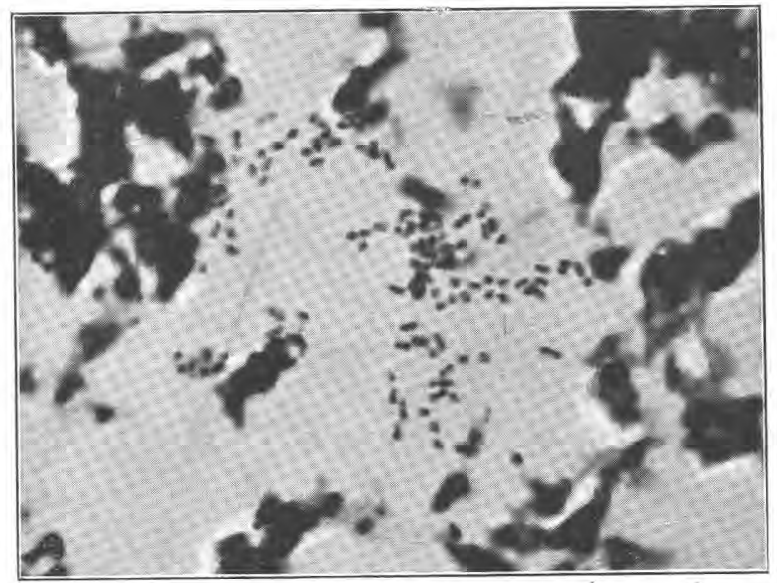

FiG. 3

Coupe de $5 \mu$ d'épaisseur d'un fromage dont le SA 30 était le levain lactique. A noter la forme caractéristique de quelques-unes des cellules

Grossissement : 1.800 fois

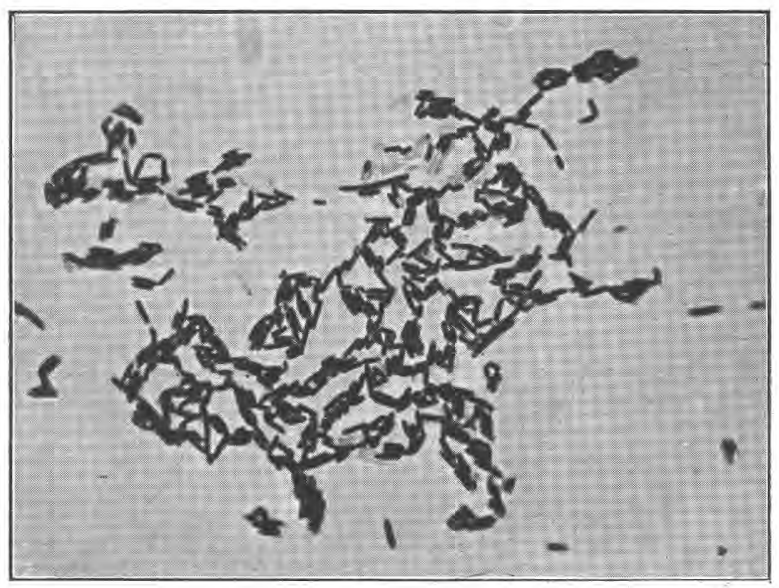

Fig. 4

Préparation par contact direct avec le fromage ci-dessus

(SA 30 levain) alors qu'il avait 34 jours. A noter les formes en baguette et le groupement des colonies ;

Grossissement : 900 fois 


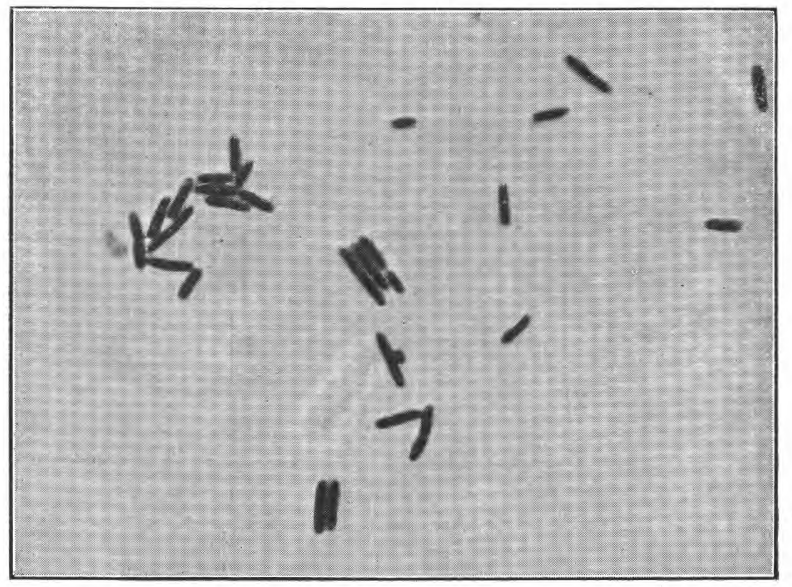

Fig. 5

Un autre champ du $n^{\circ}$ (D) 10.503 ;

Grossissement . 1.800 fois

Préparations de l'auteur. Photo-micrographies de Percy-Bentley. 
rale. Des ensemencements directs dans du lait stérile furent faits avec chaque lot de beurre, avee l'eau, et avec 7 des échantillons de crème reçus (échantillons 40,54,148, 207, 253, 293 et 301). Le lait ensemencé avec l'eau montra un caillé solide, avec décoloration du tournesol, mais aucune odeur de caramel ne fut décelée. Dans presque tous les cas, les autres ensemencements produisirent un caillé solide et une réduction du tournesol. Les ensemencements avec les échantillons 54 et 148 , en particulier, donnèrent un arôme identique à l'arôme noté en déballant le beurre indiqué par (e); et l'ensemencement par l'échantillon 207, une crème particulièrement amère, donna l'odeur de caramel.

Du beurre fait expérimentalement, avec la crème ensemencée avec des espèces tirées de l'échantillon 148 , avait un arôme et une saveur de caramel bien nets. Des cultures pures d'organismes produisant l'arôme de caramel dans le lait furent obtenus de ce beurre (1).

La nature des caillés, l'odeur nette de brûlé ou de caramel et l'arôme à l'ouverture des emballages de beurre, suggéraient un rapport entre la difficulté soumise à l'enquête et l'odeur de caramel ou de brûlé, dont je m'étais précédemment occupé. Mes recherches s'orientèrent done sur cette supposition.

Il était nécessaire de procéder à de nombreuses cultures. Des organismes donnant l'arôme caractéristique de carame] dans le lait furent isolés de chacun des trois lots de beurre, et les espèces isolées des échantillons 148 et 207 se montrèrent si nettes et si définies dans leur propriété de produire l'odeur de caramel que les études sur les autres échantillons de crème furent arrêtées. Des ešpèces représentatives ce chacune des sources ci-dessus indiquées - désignées sous le nom de séries SA pour identification - furent transportées sur gélose nutritive, dans des flacons de Freudenreich, et mises de côté pour études ultérieures.

Etude des cultures: Quand les cultures furent reprises en octobre 1925, les organismes avaient été ensemensées sur gélose, sans changement, depuis six mois.

Milieux employés: Gélatine nutritive Gélose nutritive

Difco (desséchée) [9]

Gélose additionnée de sérum

$\rightarrow$

de laiteris

Milieu pour les déterminations de la fermentation: Méthode de la gélose liquéfiée adoptée. De la gélose nutritive fut préparée,

(1) Des rreuves suffisantes de la nature spécifique du trouble soumis à l'enquête ayant. été obtenues, des instructions appropriées furent données à la laiterie en question. 
du pourpre de bromocrésol ajouté eomme indicateur, puis les hydrates de carbone nécessaires, ajoutés respectivement dans la proportion de $1 / 2$ à $1 \%$. Le milieu fut mis en tube, puis stérilisé à l'autoclave.

\section{Gélose-nitrate Voir le manuel des méthodes américaines [10]}

Lait : du lait fraîchement écrémé fut mis en tube, ou en flacons et tyndallisé dans la vapeur vive pendant trois jours successifs.

Lait au tournesol : préparé comme ci-dessus, la quantité nécessaire de teinture de tournesol de Kahlbaum étant ajoutée avant la mise en tube.

Après avoir été revivifiées sur des plaques d'agar-sérum, les espèces désignées pour l'étude étaient: la culture SAl, obtenue du beurre fait expérimentalement avec la crème ensemencée par l'organisme isolé de la crème 148 ; la culture SA 30 , représentant une culture SA 1 plus récemment repurifiée; les cultures $\mathrm{SA} 2, \mathrm{SA} 8, \mathrm{SA} 14$, du beurre échantillonné sous (c); la culture SA 3 de la crème 148; la culture SA4 de la crème 207; les cultures SA $6, \mathrm{SA} 10, \mathrm{SA} 20$, du beurre échantillonné sous ( $d$ ); et la culture SA 16 du beurre échantillonné sous (e). En raison d'une erreur, la culture SA 8 ne fut pas comprise dans les déterminations ei-dessus.

Chaque espèce prenait le Gram, ne liquéfiait pas la gélatine après 25 jours d'incubation à $21^{\circ} \mathrm{C}$. et montrait une croissance nette en 24 heures à $21^{\circ} \mathrm{C}$. sur gélose-sérum inclinée: la croissance était classée de "rare» à "modérée ».

Pour la fermentation des hydrates de carbone, des géloses liquéfiées furent employées dans toutes les déterminations, excepté pour celles du glucose. Aucun gaz ne fut produit par les hydrates de carbone essayés. Toutes les espèces donnèrent une fermentation acide avec le glucose, le lévulose et le lactose ; la saccharose eut une fermentation acide avee SA 6 et SA 16 seulement; une fermentation acide dans le gélose-maltose fut produite par SA 2, 6, 10, 14, 16, 20; le xylose fermenta avec SA 1, 6, 16, 30; la mannite avec SA 14 seulement; tous, excepté SA 4 , produisirent de l'acidité dans la salicine; la glycérine ne fermenta avec aucune espèce.

D'après les réactions notées par HAMMER et CoRdes [8], et comparées avec celles indiquées par ORLA-JENSEN dans son étude des bactéries lactiques [11], les variations enregistrées sur les hydrates de carbone ne sont pas plus grandes que celles notées en étudiant les espèces typiques de Streptococcus lactis.

\section{Action sur le lait :}

Quand les études préliminaires furent effectuées au printemps de 1925 , les eultures SA $1,10,14,16$ et 20 , furent notées comme ayant donné l'arôme caractéristique dans le lait à un degré plus ou moins grand. A la reprise de l'étude, beaucoup de transplantations 
sur gélose sérum furent effectuées, et mises à l'étuve à $21^{\circ} \mathrm{C}$ avant que les ensemencements sur lait ne furent entrepris. On observa à ce moment une assez petite variation dans l'effet sur le lait. Quelques espèces parurent donner des résultats positifs, indéterminés ou négatifs, respeetivement, au fur et à mesure que les déterminations étaient répétées ; et, dans certains cas, même la faculté de coaguler le lait sembla presque se perdre. Toujours, a près avoir été on cultures pures, pendant plusieurs mois, la propriété de produire l'arôme caractéristique de earamel dans le lait fut conservée, intacte, par la culture SA3, de la crème 148 , la culture $\mathrm{SA} 30$, une repurification de la culture SA 1 , la culture $\mathrm{SA} 4$, de la crème 207, et la culture SA 8, du beurre qui avait été emmagasiné.

N. B. - La culture SA8, qui avait été précédemment oubliée, fut incluse dans les déterminations faites sur le lait.

Il faut noter qu'il n'y a pas de corrélation apparente entre la faculté de produire l'arôme de caramel dans le lait et la réaction des diverses espèces sur les hydrates de carbone employés. Une étude plus détaillée a été faite de la culture SA30.

\section{Étude de la culture SA 30 :}

L'histoire de cette eulture, qui remonte à la crème originelle 148 , a été donnée à la page 128. Avant que l'espèce ne fut soumise à l'étude ci-dessus, elle était passée par du beurre expérimental, avait été repurifiée, et transférée plusieurs fois sur gélose et gélose-sérum.

Microscopiquement, l'organisme prend le Gram et apparaît sous la forme d'une cellule ovoïde, parfois isolée, plus souvent par paires, avec quelques grappes et quelques rares chaînes, quand on fait des préparations avec une culture jeune sur gélose-sérum. (Fig. 1).

Sur gélose-sérum inclinée, la croissance passe de rare à modérée en 24 heures: 1'espèce se développe bien à $37^{\circ} \mathrm{C}$. et à $21^{\circ} \mathrm{C}$, particulière ment bien à $30^{\circ} \mathrm{C}$, et une croissance perceptible est observée à $11^{\circ}$. $12^{\circ} \mathrm{C}$. Dans les cultures ensemencées par piqure sur gélose et gélosesérum, la croissance est bonne le long de la ligne de piqûre, filiforme, modérée, avec peu ou pas de croissance à la surface de la piqure. Sur plaques de gélose-sérum, la majorité des colonies est sous la surface, et elles sont denses avec contours complets. Les nitrates, quand on emploie de la gélose-nitrate, ne sont pas réduits en nitrites. La gélatine n'est pas liquéfiée. II ne se forme pas d'indol. Aucun gaz ne se produit dans les milieux avec hydrates de carbone.

En employant de la gélose liquéfiée, le dextrose, le levulose, le galactose, le lactose, le mannose, la salicine et le xylose fermentent et donnent de l'acidité; le saccharose, la mannite, l'inuline, la glycérine et l'arabinose ne fermentent pas. La température la plus convenable pour la croissance semble être aux environs de $30^{\circ} \mathrm{C}$. 
Dans le lait tournesolé, la croissance est rapide; le tournesol est décoloré et un caillé ferme et solide se forme, sans digestion, en 24 heures à $30^{\circ} \mathrm{C}$. et $21^{\circ} \mathrm{C}$., respectivement: l'odeur caractéristique de caramel peut être perçu avant que la coagulation n'ait lieu. Des flacons à large col conviennent mieux pour percevoir l'arôme et les expériences décrites ci-après doivent être consultées.

L'organisme est tué après 10 minutes à $62^{\circ}-63^{\circ} \mathrm{C}$. dans un bainmarie de de Kotinsixy, quand une goutte d'une pipette de 1 ec d'une culture jeune de sérum ou de lait est ajoutée à environ $7 \mathrm{cc}$. de lait.

\section{SA30 dans le lait:}

L'arome earactéristique est donné dans le lait complet frais, le lait écrémé tyndallisé et le lait écrémé stérilisé suivant la méthode habituelle des laboratoires.

0,1 cc. d'une culture vigoureuse de lait ensemencée dans 400 cc. de lait stérile donna une odeur nette de caramel en 19 heures à $21^{\circ} \mathrm{C}$., le lait se caillant 2 heures après; 0,5 cc. ensemencés dans 400 cc. donnèrent un arôme plus fort. Avec un ensemencement à $1 \%$, l'arôme fut observé en 7 heures à $21^{\circ} \mathrm{C}$., en 5 heures $1 / 2$ à $30^{\circ} \mathrm{C}$. et, dans un cas, $\mathrm{e}^{\mathrm{n}} 4$ heures. Avec un ensemencement à $0,5 \%$ du $26^{\mathrm{e}}$ passage dans le lait, l'arôme fut produit en 20 heures à $21^{\circ} \mathrm{C}$. Trois semaines plus tard, une légère odeur de caramel existait, et on pouvait déceler une odeur de brûlé ou de roussî. A $11^{\circ} \mathrm{C} .-12^{\circ} \mathrm{C}$, l'arôme est produit si on laisse se prolonger une longue période d'incubation, et une légère odeur de fromage peut se remarquer au moment de la coagulation.

Au fur et à mesure de l'étude, on observa que le degré auquel l'odeur persistait, variait. Dans de rares cas, une légère odeur putride fut observée en supplément de celle de caramel. On a aussi trouvé que dans des cultures de lait ensemencées à $21^{\circ} \mathrm{C}$., l'organisme semble disparaître en 2 à 4 semaines. Du lait stérile, et des flacons à large col furent employés dans les nombreuses déterminations dont celles indiquées ci-dessus sont les plus typiques.

Dans le lait écrémé; passé à la vapeur pendant 20 minutes, un ensemencement à $0,05 \%$ donna l'arôme en 19 heures à $21^{\circ} \mathrm{C}$., la coagulation se produisant après.

\section{Arome caractéristique dans le lait:}

L'arome est tant soit peu doux, ressemblant un peu aux bonbons dits: caramels au beurre, et d'une manière caractéristique au caramel. Dans quelques cas, on sent le malt; dans d'autres cas, l'odeur est de roussi ou de brûlé; et dans quelques rares cas, le vrai caramel est accompagné par une odeur légèrement putride. L'intensité de l'arôme a quelque rapport avec le pourcentage de produit ensemencé utilisé. 
Quand l'organisme ensemenceur est vigoureux et bien habitué au lait, l'odeur ou l'arome de earamel, spécifique et distinct, ne peut pas être prise pour une autre. L'odeur peut persister quelques jours.

Goût caractéristique dans le lait.

La saveur typique est acide, piquante distinctement de caramel, quelquefois de brûlé et occasionnellement amère. Les dents sont agacées, et, souvent une sensation désagréable de brûlé est ressentie sur la langue, sur le palais et au fond de la gorge. La sensation de "brûlé " est plus particulièrement ressentie quand le lait a 2 à 3 jours, et l'effet dure de 15 à 20 minutes.

Acidité volatile.

Mon collaborateur, le Professeur N.-S. GoLDING, détermina, en employant la méthode décrite en détail par HAMMER et BATLEX [12], l'acidité volatile de la culture SA30. Il trouva que l'acidité volatile était de 4,8 , chiffre légèrement plus bas que celui indiqué par HaMmer et Cordes [8], dans l'étude de leur espèce productrice de caramel. Ces expérimentateurs notent que les valeurs trouvées par eux étaient essentiellement les mêmes que les valeurs trouvées avec les cultures types de Streptococcus lactis. Suivant HaMmer et Cordes [8], on peut admettre que la culture SA 30 ne montre aucune différence avec les véritables types de Streptococcus lactis, en ce qui concerne l'acidité volatile.

Classification.- A part sa qualitéde producteur de carameldans le lait, les caractéristiques de cet organisme le elassent comme une variété de Streptococcus lactis (Lister), OrLA-Jensen [11], Bergey (S A B) [13]. Lefait que l'organisme ne donne pas d'acidité avec la maltose et la mannite rappelle le Streptococcus cremoris d'ORLA-JENSEN ; précisément, dans leur ensemble, les caractéristiques se rapprochent très près de la morphologie et des réactions des espèces de Streptococcus lactis étudiées par lui. La propriété de produire l'odeur de caramel, ainsi qu'il a été observé par HAMMER et CORDES [8], pourrait suggérer une différenciation d'espèce. Comme, cependant, la culture SA 30 paraît être identique avec l'organisme décrit précédemment par moi sous le nom de Bacterium lactis acidi (LeichmanN) [1], aussi avec l'organisme décrit par HaMmer et Cordes sous le nom de Streptococcus Lacticus [8], et comme OrLA-JENSEN indique que le Streptococcus lactis donne au lait et à la crème, soit un goût purement acide, soit une saveur déplaisante, il est suggéré que la culture $\mathrm{SA} 30$ soit classée comme Streptococcus lactis (LISTER) [11] [13]. Si, pour les intérêts de la spécificité, la proposition de Hammer et Cordes [8] est avantageuse, il y a, semble-t-il, de bonnes raisons pour classer l'organisme comme Streptococcus lactis (Lister) var. maltigenus. 
SA 30 dans le beurre. - 30 livres $(13 \mathrm{~kg}$. 600) de crème douce, récemment écrémée, furent pasteurisées à $170^{\circ} \mathrm{F}$. $\left(76^{\circ} 6 \mathrm{C}\right.$.) pendant 10 minutes, puis, après refroidissement, ensemencées avee une culture vigoureuse de lait de SA 30 dans la proportion de $1 \%$. La crème fermenta pendant 16 heures dans la laiterie à la température d'environ $60^{\circ} \mathrm{F}$. ( $15^{\circ} 5 \mathrm{C}$.). En enlevant le couvercle du bac, on sentait nettement l'odeur de caramel dans le bâtiment. La crème fut divisée en deux lots. 15 livres $(6 \mathrm{~kg}$. 800$)$ furent barattées de suite; le reste fut neutralisé avec de la chaux jusqu'à une acidité de $0,15 \%$ puis baratté. A l'examen, le beurre terminé avait une odeur et une saveur de caramel fortes et caractéristiques; et aussi un goût doux, légèrement nauséabond. Deux semaines plus tard, l'odeur et la saveur de caramel étaient très nettes; la saveur était légèrement nauséabonde et une sensation de brûlé était produite sur la langue.

Une partie du beurre, conservée à la température du laboratoire, fut examinée trois mois après la fabrication. Ni odeur, ni saveur de caramel ne purent être décelées dans le beurre fait avec la erème neutralisée ; mais l'odeur était désagréable. L'autre beurre avait une saveur faible de caramel, et une odeur indiquant une détérioration généralisée. Les deux étaient absolument immangeables, quelque peu nauséabonds, et avaient un effet de "brûl $\hat{~}$ " très net sur le palais. En ensemençant du lait avec chacun des deux échantillons, on produisit l'arôme caractéristique de caramel après fermentation à $30^{\circ} \mathrm{C}$. Le beurre de crème neutralisée fut éliminé. On isola en culture pure l'organisme de l'autre échantillon, et la faculté de produire l'adeur de caramel dans le lait sembla s'être accentuée. Les déterminations par cultures furent effectuées, l'identité de l'organisme vérifiée, et l'espèce renouvelée est en collection sous le nom de culture SA30 B.

En ce qui concerne la possibilité de faire disparaitre l'arôme et la saveur de caramel par pasteurisation et neutralisation, les travaux de HAMMER et Cordas [8] semblent être décisifs et doivent être consultés. Ils indiquent ce qui suit : " La saveur de caramel illustre bien ce qu'est une saveur qui, une fois présente dans la crème, sera certainement, avec les méthodes actuelles, présente aussi dans le beurre $\%$.

Des échantillons du beurre expérimental décrit ei-dessus furent apportés au Congrès Annuel des Laitiers d'Alberta, à Edmonton, en janvier dernier. J'eus la chance d'avoir l'opinion de plusieurs experts compétents et hommes de laboratoires sur la saveur de l'arôme de ces échantillons. A ce moment, chaque échantillon avait 3 semaines. Le Dr E. G. Hood, ehef des Recherches, Mr. J. F. Singleton, chef des Marchés, et Mr. Jos. Burgess, chef des Experts de l'Etat, de la Section laitière d'Ottawa; Mr. W. A. Wrison, représentant des Produits Agricoles Canadiens à Londres; Mr. L. A. Grbson, Commissaire de 
la Laiterie pour le Manitoba ; et le Professeur C. P. Marker, d'Alberta, confirmèrent tous la terminologie employée par moi pour définir et décrire à la fois l'arôme et la saveur.

Ultérieurement, le Professeur Marker [14] m'envoya une note dont j'extrais ce qui suit : « Vous vous rappelez que quand vous m'avez montré, lors de votre visite ici, les échantillons de beurre à la saveur de caramel que vous aviez apportés de Vancouver, je vous avais dit que cette saveur était identique à celle que nous appelions "saveur de chauffé n dans nos travaux de classement par points du beurre [15]. A cet égard, je trouve que sur les 1.225 barattages elassés par points pendant la saison de 1908,62 , ou $5 \%$, furent trouvés avoir cette note. Je ne pense pas avoir de renseignements plus anciens sur ce sujet dans nos propres travaux »... "En consultant des ouvrages danois, je pense que leur terme "branket" est équivalent à votre expression: saveur de "caramel", trouvée dans les échantillons apportés par vous à Edmonton $\% . .$.

... « \$товсн [16] (1890) fait allusion au défaut "branket» qu'il a trouvé dans des lots de beurre à 7 grands concours beurriers, tenus de 1878 à 1888. Il indique que sur 79 lots de beurre centrifuge exposés à Odense en 1888, 15,4\% furent trouvés "branket».

Le Professeur Marker donne ensuite une traduetion du danois de l'ouvrage très documenté de $\mathrm{C}$. $\mathrm{O}$. Jensen [17] (1891). Parmi les organismes isolés par JENSEN, une espèce, KA 4, était un petit organisme ovale, apparaissant par paires, qui ressemblait à certains organismes lactiques en dépit du fait qu'il ne changeait pas l'apparence du lait. L'espèce donnait au lait une odeur et une saveur douceâtres très prononcées de "Branket » qui lui rappelait une préparation maltée tonique appelée "Albumen-Maltose ". JENSEN isola l'organisme en opérant sur de la crème qui avait un arôme "Branket" et une saveur de malt. Il trouva que le beurre fait avec la crème avait précisément les mêmes arôme et saveur, et remarque que l'arôme pouvait être décelé immédiatement en entrant dans la laiterie dans laquelle le lait, la crème et le beurre étaient conservés.

Les observations du Professeur MARKER, sur les rapports de l'arôme et de la saveur de earamel avec le défaut de "chauffé " trouvé à un moment dans le beurre classé sous sa direction, sont d'un intérêt particulier. Ses citations de la littérature danoise, à laquelle je n'ai pas accès d'habitude, sont de la plus grande valeur. Il semble plus que pro. bable que quelques-uns des organismes signalés par C.-O. JENSEN sont identiques, ou très proches, des espèces rencontrées par Me DonNELL (1899), Sadler (1911), Leitch (1918), Hammer et Cordes (1921) et de celles discutées dans le présent travail. Une différence très nette réside toutefois dans l'incapacité pour l'organisme de JENSEN de cailler le lait. De la deseription donnée des caractéristiques au point de vue cul- 
ture de son espèce KA 4, il est à peine possible de l'identifier spécifiquement avec l'espèce décrite ici; mais de la description du "défaut", c'est-à-dire de l'arôme et de la saveur extraordinaires du beurre, l'identité de cette espèce avec celles décrites ultérieurement, et avec la culture SA30, apparaît être très probable.

SA 30 dans le fromage. - L'action de l'organisme produisant le goût de caramel dans le fromage ayant été observée en 1911 [11] et par LеIтCH [4] (1918), il était évident qu'une fabrication de fromage avec un lait ensemencé avec SA30 s'imposait. Ce lait fut pasteurisé à $142^{\circ}-145^{\circ} \mathrm{F}$. $\left(61^{\circ} 11-62^{\circ} 77 \mathrm{C}\right.$.) pendant 30 minutes, refroidi, et ensemencé, dans la proportion de $3 / 4 \%$, avec une culture de lait SA30 comme starter. Le starter avait distinctement l'arome de caramel : le goût était celui du caramel, acide, piquant, et "brûlé " au palais. On employa assez de lait pour faire 12 fromages de Kingston (1). Ce fromage, pesant 1 livre $(0 \mathrm{k} .453)$, se prête remarquablement bien à un tel essai. II est du type dur pressé, et est mûr 2 à 3 semaines après la fabrication [18] [19] [20].

En outre, on peut observer le fromage fait de temps en temps, en ayant toujours un fromage entier, non sondé, pour chaque examen. Pendant la fabrication, l'arôme de caramel fut très fort dans le laboratoire, et l'air fut saturé d'une odeur douce nauséabonde. 20 minutes après addition du starter au lait dans le bae, l'odeur caractéristique était nette, et quand les eaillés furent chauffés dans le sérum, l'odeur était prononcée. La production d'acide fut plus rapide qu'à l'habitude; dans son ensemble, le fromage était ferme et, plus tard, eut les qualités d'un fromage trop acide, fait avec du lait trop sûr; ceei, malgré que la méthode choisie fut comparable à celle suivie dans la fabrication du fromage de Kingston, semaine par semaine [20]. La forte production d'acide pendant la fabrication, et la condition trop acide du fromage semblent coincider exactement avec l'expérience de LeIтcH [4], quand il fit du fromage de Cheddar avec l'espèce productrice de caramel isolée par lui.

Des coupes histologiques du caillé furent préparées au moment du passage au moulin, fig. 3 , et à divers moments après que le fromage fut placé en chambre de maturation. Des préparations par contact direct furent aussi faites du fromage pendant la maturation, (fig. 4.). Les méthodes employées sont indiquées par moi dans une autre étude [20]. On voit (fig. 3), qu'au moment du passage au moulin, les organismes ajoutés comme starter prédominent. Sur la fig. 4 , représentant une préparation par eontact direct quand le fromage avait 34 jours, on voit des bâtonnets, et les organismes producteurs de

(1) Les fromages furent faits au laboratoire de laiterie par Mr. W I. CARPENTER. 
caramel du starter sont absents. Entre temps, les fromages ne mûrissaient pas, étaient durs et secs, et n'avaient aucune des qualités attribuées au fromage de Kingston type. Les formes en bâtonnet qui apparaissent à la maturité du fromage, ainsi que l'ont montré KELLY [19] et SADLER [20], étaient présentes.

12 jours, 19 jours, 34 jours, et 4 mois après la fabrication, on a examiné un fromage non troué par la sonde. A aucun moment, on ne trouva le fromage mûr. Lors des $1^{\mathrm{er}}$ et $2^{\mathrm{e}}$ examens, l'arôme de caramel était très net et, au $4^{\mathrm{e}}$ examen, l'odeur pouvait encore être notée, Au $2^{\mathrm{e}}$ examen, en particulier, on nota, en dégustant le fromage, un effet sur le palais de "brâlé " très net. Lors des $1^{\mathrm{e}}, 3^{\mathrm{e}}$ et $4^{\mathrm{e}}$ examens (aucun ensemencement ne fut pratiqué lors du $2^{\mathrm{e}}$ examen), des morceaux de fromage ensemencés directement dans le lait, donnèrent l'odeur earactéristique de caramel à $30^{\circ} \mathrm{C}$. Dans chaque cas, l'organisme reprís en culture pure, dans du lait, produisit l'arôme de caramel. La plaque par contact direct faite lors du $3^{\mathrm{e}}$ examen, (fig. 4), montre pratiquement une culture pure de bâtonnets ; pourtant, l'organisme producteur de caramel était présent, ainsi que le prouvaient l'effet du fromage ensemencé dans le lait, et la réapparition de l'espèce en culture pure. L'identité de cet organisme avec le SA30 originel a été établie, et l'organisme est en collection sous le nom de culture SA $30 \mathrm{~K}$. Quand on ensemence SA $30 \mathrm{~K}$ dans le lait stérile, l'arôme de caramel produit est très net et caractéristique, et, si possible, la faculté de cet organisme de produire l'odeur de caramel est accentuée.

Comme l'organisme producteur de caramel est un Streptococcus lactis, il est intéressant de le trouver vivant dans un fromage de 4 mois, fromage qui est normalement mûr 2 à 3 semaines après fabrication, et qui, à 34 jours, a l'apparence microscopique de la fig. 4 . Il est possible qu'un mélange judicieux de l'organisme producteur de caramel avec un starter puisse servir d' "indicateur" et aider aux recherches des rapports qui existe entre le type Streptococcus lactis (Iister) et la maturation du fromage.

Moyens de prévention et remèdes. - Comme l'organisme cause de l'arome et de la saveur de earamel est une variété de Streptococcus lactis (Lister), on n'en peut pas dire grand'chose, en dehors de la bonne application d'une pratique basée sur une connsaissance intelligente de la bactériologie. L'organisme n'est pas difficile à tuer. $\mathrm{Si}$ on emploie les méthodes modernes, le lait et la crème étant classés par qualité, l'infection sera décelée par l'arôme et la livraison contaminée mise à part. La pasteurisation du lait, ou de la crème, faite suivant les règles actuelles, détruira l'organisme producteur de caramel, mais pas l'arôme et la saveur. Un nettoyage complet de tous les appareils et instruments, de l'outillage, et un passage 
à la vapeur vive, empêcheront et éviteront le développement de l'infection quand une contamination initiale aura eu fieu, à eondition que les procédés ci-dessus recommandés soient suivis. Tous les renseignements de laboratoire indiquent qu'une fois que l'arôme et la saveur se sont formés dạns le lait, ni la crème, ni l'arôme, ni la saveur, ne peuvent être enlevés par les procédés ou traitements existants.

\section{Résumé}

15.000 livres de beurre, fabriquées dans une laiterie de la Colombie Britannique, furent trouvées impropres à la vente, en raison d'une saveur spéciale et inacceptable.

Des échantillons de beurre frais, de beurre qui avait été en magasin, et de crèmes de divers fournisseurs, furent examinés. Une partie du beurre avait une odeur et une saveur nettes de caramel à l'arrivée au laboratoire.

Des organismes qui produisaient une odeur et une saveur de caramel dans le lait furent isolés en culture pure de chacun des échantillons de beurre et de certains des échantillons de crème.

Les organismes furent trouvés être des espèces typiques de Streptococcus lactis (Lister), avec cette exception qu'ils produisaient l'odeur et la saveur de caramel dans le lait. Une étude plus détaillée a été faite de la culture SA 30. L'intensité, aussi bien de l'odeur que de la saveur, dans le lait, varie, dans une certaine mesure, avec la proportion du produit contaminant.

Le beurre fait expérimentalement avec de la crème infectée a l'odeur et la saveur typiques, et un organisme, qui a conservé ses caractéristiques spécifiques, a été retiré de ce beurre âgé de trois mois.

Du fromage fait avec du lait ensemencé avec l'organisme devient trop acide, accuse le défaut, ne vient pas à maturation, et est tout à fait immangeable. L'organisme, conservant ses propriétés spécifiques, a été isolé d'un tel fromage 4 mois après la date de fabrication.

L'arome et la saveur caractéristiques produits dans le lait sont définis dans l'étude précédentę.

L'organisme doit être considéré comme étant un Streptococcus lactis (Lister) [11] [13] ou, si on accepte actuellement la suggestion de Hammer et Cordes, un Streptococcus lactis (Lister) [13] var. maltigenus [8].

Note.

Je remercie le Professeur N.-S. Golding, de mon Service, qui a effectué certaines déterminations chimiques et surveillé la fabrication du beurre expérimental. Il m'est agréable de noter la généreuse amabilité montrée par le Professeur C.-P. Marker, qui m'a communiqué des eitations de la littérature danoise, et qui a examiné d'une façon 
critique et noté le beurre expérimental fait avec la crème infectée. Mes remerciements sont aussi dûs à l'Université de la Colombie Britannique pour les facilités qui ont rendu possible la présente étude.

$$
\text { *** }
$$

Addendum. - Comme la rédaction de ce travail approchait de sa fin, la culture S.A. 30 perdit la propriété de produire l'odeur et le goût de caramel : une odeur et un goût indésirables étaient évidents, mais ceux de caramel ne pouvaient être observé. La eapacité de cailler le lait s'affaiblissait. Les réactions vis-à-vis des sucres et la culture sur milieux artificiels ne semblaient pas troublés. Des échantillons qui avaient été mis en stock trois mois auparavant et des échantillons restant en laboratoire depuis 1 ou 2 mois montrèrent qu'ils avaient conservé la capacité de produire l'odeur et le goût caractéristiques dans le lait. Les cultures S. A. 30 B. et S. A. 30 K. provenant respectivement du beurre et du fromage expérimentaux (voir le texte) se montrèrent typiques et caractéristiques sous tous les rapports. La capacité de produire l'arôme et le goût caractéristiques du caramel n'a pas été du tout troublée.

Cette étude semble suggérer que l'organisme demande de temps en temps une période de repos.

\section{BIBLIOGRAPHIE}

[1] SADLER, Wilfrid, 1911. Note sur un organisme produisant un goût de lait brûlé. Central. für Bakt, 11, Abt. 291, 1-3.

[2] Duclaux, E. Principes de Luiterie, pp. 98 et 99, Armand Colin et Cie, Paris.

[3] Weigmann, H., 1911, Mycologie du lait, pp. 184, 211, Leipzig.

[4] Leitch, Renwick, H., 1918. La saveur de brillé dans les produits laitiers causée par le "Streptococcus lacticus." Bull. West of Scotland Agr. coll. pp. 21 and 22, Glascow.

[5] SADLER, Wilfrid et VoLLUM, R. L., 1923. Classement du beurre d'après sa contenance en bactéries. The advisory Council for Research, Ottawa (Mss).

[6] Kayser, E., 1921. Microbiologie Agricole, p. 310, Baillière et Fils, Paris.

[7] Jensen-OrLA, (Trad. par ARUP) 1921. Bactériologie laitière, p. 118, J. and Churehill, London.

[8] Hammer, B. W., and Condes, W. A., 1921. Saveur de brulle ou de caramel des produits laitiers. Research Bull. No 68, Agr. Exp. Sta., Ames, Iowa.

[9] Digestive Ferments Company, Detroit, Michigan.

[10] Socy. Amer. Bact. Committee, 1923, Manuel des Méthodes, Geneva.

[11] JENSEN-ORLA, 1919. Les bactéries lactiques (en anglais). D. Kgl. Danske Vidensk. Selsk. Skrifter, Naturv, og. Mathematisk Afd., 8, Raekke, V. 2. Kjobenhavn.

[12] Hammer, B. W., et Bamey, D. E., 1919. La production $d^{\mathrm{r}}$ acides volatils des starters et des organismes qui en sont isolés. Research Bull., № 55, Agr. Exp. Sta., Ames, Iowa.

[13] BErgex, (SAB) 1923, Bactériologie, p. 53, Williams and Wilkins, Baltimore. 
[14] Marker, C. P., 1926. Communication personnelle.

[15] Marker C. P. Carte de classement de beurre par points, Form. D. 16, 30005-14, Alberta, Dept. of Agr.

[16] Sтовсн V. 1890 (Trad.), 18 Rapport du Laboratoire de Recherches agricoles. Laboratoire de Recherches Agricoles. Copenhague.

[17] Jensen, C. O., 1891 (Trans.) 32e Rapport du Laboratoire de Recherches $d u$ Collège Royal Vétérinaire et Agricole. Copenhague. p. 24 et p. 59.

[18] Todd, Alex. et SAdLer, Wilfrid, 1911, Le fromage de Kingston, Jour. Bd of Agr. XVIII, 3, pp. 193-203, London.

[19] KenLy, C. D., 1924, La bactériologie du fromage de Kingston. Trans Roy. Socy. Can. 3e Série, XVIII, pp. 51-59, Ottawa.

[20] SADLER, Wilfrid, 1926, La flore bactérienne du fromage de Kingston montrée par les micro-photographies. Trans. Roy. Socy. Can. et Le Lait 1927, $\mathrm{n}^{\circ} 1$.

\title{
LES INDICATEURS ET L'ACIDITÉ TOTALE ET RÉELLE DU LAIT
}

\author{
par $\mathrm{D}^{\mathrm{r}}$ Alb. J.-J. VANDEVELDE
}

Professeur à l'Institut Supérieur Agronomique et à l'Université de Gand, Directeur de i'Institut Supérieur des Fermentations.

La détermination de l'indice de la concentration en ions hydrogène, que Sörensen a désigné par le symbole $\mathrm{pH}$, et que Clark a proposé de nommer degré Sörensen (1), se fait par voie électrique et par voie colorimétrique. La méthode électrique est sans doute la plus exacte, quand elle est adroitement et souvent appliquée; la méthode colorimétrique est peut-être moins précise, mais elle est d'exécution rapide et facile, et elle offre l'avantage d'être à la portée de chacun.

La méthode colorimétrique n'est cependant bien applicable qu'à des liquides transparents : les liquides troubles, les solutions colloïdales ne peuvent pas toujours être employés. Le lait est dans ce cas; les colorants de Sörensen, ceux de ClaRK et LuBBS donnent des résultats très irréguliers; ceux de MicHAfLIs ne sauraient être employés. Il est préférable de transformer, pour l'emploi des indicateurs, les liquides colloïdaux en solutions limpides.

Schultz et Chaudler (2) ont proposé de déterminer le degré Sörensen en dialysant le lait à l'aide d'un sac de collodion; ils emploient un volume de lait et comme récepteur 2 volumes d'eau distillée très pure, puis ils soumettent le dialysat à l'examen colorimétrique. Ils ont trouvé ainsi $\mathrm{pH}=6.53$ en moyenne, entre 6,7 et 6,4 pour le lait de chèvre, $\mathrm{pH}=7,22$ pour le lait humain.

(1) The determination of hydrogen ions; Baltimore, 1922, p. 13.

(2) The acidity of goats milk in terms of hydrogen ion concentration, with cotaparisons to that of eow's and human milk; Journ. biol. Ohem., t. 46, pp. 129-131. 